ALD Functionalized Nanoporous Gold: Thermal Stability, Mechanical Properties, and Catalytic Activity

M. M. Biener, J. Biener, A. Wichmann, A. Wittstock, T. F. Baumann, M. Baeumer, A. V. Hamza

March 24, 2011

Nanoletters 
This document was prepared as an account of work sponsored by an agency of the United States government. Neither the United States government nor Lawrence Livermore National Security, LLC, nor any of their employees makes any warranty, expressed or implied, or assumes any legal liability or responsibility for the accuracy, completeness, or usefulness of any information, apparatus, product, or process disclosed, or represents that its use would not infringe privately owned rights. Reference herein to any specific commercial product, process, or service by trade name, trademark, manufacturer, or otherwise does not necessarily constitute or imply its endorsement, recommendation, or favoring by the United States government or Lawrence Livermore National Security, LLC. The views and opinions of authors expressed herein do not necessarily state or reflect those of the United States government or Lawrence Livermore National Security, LLC, and shall not be used for advertising or product endorsement purposes. 


\title{
ALD Functionalized Nanoporous Gold: Thermal Stability, Mechanical Properties, and Catalytic Activity
}

\author{
Monika M. Biener, ${ }^{*}$, Juergen Biener, ${ }^{1}$ Andre Wichmann, ${ }^{2}$ Arne Wittstock, ${ }^{2}$ Theodore F. \\ Baumann, ${ }^{1}$ Marcus Bäumer ${ }^{2}$ and Alex V. Hamza ${ }^{1}$ \\ 1) Nanoscale Synthesis and Characterization Laboratory, Lawrence Livermore National Laboratory, 7000 East Ave, \\ Livermore, CA 94550 \\ ${ }^{2)}$ Institute of Applied and Physical Chemistry, University Bremen, Bremen, Germany \\ * Corresponding author: Biener3@, llnl.gov
}

Nanoporous metals have many technologically promising applications but their tendency to coarsen limits their long-term stability and excludes high temperature applications. Here, we demonstrate that atomic layer deposition (ALD) can be used to stabilize and functionalize nanoporous metals. Specifically, we studied the effect of nanometer-thick alumina and titania ALD films on thermal stability, mechanical properties, and catalytic activity of nanoporous gold (np-Au). Our results demonstrate that even only one-nm-thick oxide films can stabilize the nanoscale morphology of $n p-A u$ up to $1000^{\circ} \mathrm{C}$, while simultaneously making the material stronger and stiffer. The catalytic activity of np-Au can be drastically increased by $\mathrm{TiO}_{2} \mathrm{ALD}$ coatings. Our results open the door to high temperature sensor, actuator, and catalysis applications and functionalized electrodes for energy storage and harvesting applications.

KEYWORDS: nanoporous gold, alumina, titania, atomic layer deposition, core-shell structures, nanoindentation, catalysis 
Nanoporous metals such as nanoporous gold (np-Au) prepared by dealloying have recently attracted considerable interest fueled by their potential use in catalysis ${ }^{1-6}$, sensor ${ }^{3,7-12}$ and actuator applications. ${ }^{13-15}$ The remarkable properties of these materials are a consequence of their characteristic bicontinuous nanoporous structure of interconnected nm-sized pores and ligaments that is formed by a self-organization process. ${ }^{16,17}$ A disadvantage of this nanoscale morphology in the context of applications is that it is thermodynamically unstable and prone to coarsening. ${ }^{10}$, ${ }^{18,19}$ For example, the length scale of both ligaments and pores of np-Au increases by more than two orders of magnitude by heating the material to $800^{\circ} \mathrm{C} .{ }^{18}$ Coarsening severely limits the practical applications of np-Au as it leads, for example, to a loss of catalytically active surface and reduces the mechanical strength ${ }^{20}$ that is important for the actuator application. Consequently, several strategies have been tested to increase the thermal stability of this material. For example, the stability can be improved by adding small amounts of high melting point metals such as $\mathrm{Pd}^{7}$ and $\mathrm{Pt},{ }^{21,22}$ or by using surface chemistry to suppress surface diffusion. ${ }^{23}$ But even 'stabilized' np-Au has only limited thermal stability as, for example, annealing of Pt-stabilized np-Au leads to severe coarsening at $400{ }^{\circ} \mathrm{C},{ }^{24}$ and stabilizing surface oxygen starts to desorb around $200{ }^{\circ} \mathrm{C} .^{23}$

In the present study we explore the potential of atomic layer deposition (ALD) to improve the thermal stability and mechanical properties of bulk np-Au beyond the currently achieved temperature regions which, for example, could open the door to high temperature sensor and actuator applications. ${ }^{13-15}$ At the same time, our study aims at elucidating whether the deposition of an oxide on the inner surfaces of np-Au can also boost its catalytic properties as it is known that the combination of $\mathrm{Au}$ and reducible oxide, such as titania, leads to highly active catalysts. ${ }^{25}$ Combined with an increased thermal stability this could enable high temperature catalytic applications of np-Au that are not yet possible. ALD is ideally suited to apply nanometer thick, uniform and conformal coatings to high aspect ratio materials such as bulk np-Au. ${ }^{26-28}$ ALD is also a wafer-compatible technology and thus could be used to modify wafer-supported np-Au films. ${ }^{29}$ Qian et al. ${ }^{30,31}$ first successfully used ALD to tune the optical properties of 100-nm-thick $\mathrm{np}-\mathrm{Au}$ films by partially or completely filling the pores with $\mathrm{Al}_{2} \mathrm{O}_{3}$. In the present study we selected $\mathrm{Al}_{2} \mathrm{O}_{3}$ for its thermal stability, ${ }^{32,33}$ and $\mathrm{TiO}_{2}$ for its potential to add functionality for catalytic, photocatalytic, solar energy harvesting, and energy storage applications. ${ }^{34-37}$ For example, ALD $\mathrm{TiO}_{2}$ thin films can be used as active cathode material in nanostructured Li-ion batteries, ${ }^{37}$ and $\mathrm{TiO}_{2}$ nanoparticle decorated np-Au is an efficient electrode material for photocatalytic oxidation of methanol. ${ }^{36}$

Our experiments reveal that even only one-nm-thick $\mathrm{Al}_{2} \mathrm{O}_{3}$ films can stabilize the nanoscale morphology of nanoporous gold up to $1000^{\circ} \mathrm{C}$, i.e. close to the melting point of bulk gold (1064 ${ }^{\circ} \mathrm{C}$ ), while making the material stronger and stiffer. The thermal stability of $\mathrm{TiO}_{2}$-coated np-Au is lower than that of $\mathrm{Al}_{2} \mathrm{O}_{3}$-coated $\mathrm{np}$-Au, but still much higher than that of the uncoated material. Here, annealing transforms the initial uniform and continuous $\mathrm{TiO}_{2}$ layer into highly dispersed $\mathrm{TiO}_{2}$ nanoparticles which increases the catalytic activity of np-Au for $\mathrm{CO}$ oxidation by almost $300 \%$.

Disk-shaped samples of np-Au (diameter $\sim 5 \mathrm{~mm}$, thickness 200-300 microns) with a porosity of $\sim 70 \%$ were prepared by selective dissolution (dealloying) of $\mathrm{Ag}_{0.7} \mathrm{Au}_{0.3}$ alloy samples in concentrated nitric acid ( $48 \mathrm{hrs}, \sim 65 \mathrm{wt} \% \mathrm{HNO}_{3}$ ) as described previously. ${ }^{39}$ The average 
ligament diameter for each sample was determined from ligament diameter distributions that were obtained by geometrical evaluation (i.e., measuring the diameter of randomly selected ligaments at their center point). These average values are those displayed in Figure $2 \mathrm{a}$. The ligament diameter of the as-prepared material is $\sim 54 \mathrm{~nm}$, and its specific surface area is $\sim 3.6$ $\mathrm{m}^{2} / \mathrm{g}$.

Nanometer-thick $\mathrm{Al}_{2} \mathrm{O}_{3}$ and $\mathrm{TiO}_{2}$ films were deposited by ALD using the well-established trimethyl-aluminum $\left(\mathrm{AlMe}_{3} / \mathrm{H}_{2} \mathrm{O}\right)^{28}$ and titanium tetrachloride $\left(\mathrm{TiCl}_{4} / \mathrm{H}_{2} \mathrm{O}\right)^{40} \mathrm{ALD}$ processes in a warm wall reactor (wall and stage temperature of $125{ }^{\circ} \mathrm{C}$ for $\mathrm{Al}_{2} \mathrm{O}_{3}$ and $110{ }^{\circ} \mathrm{C}$ for $\mathrm{TiO}_{2}$ ). Both ALD processes are ideally suited to coat high aspect ratio materials such as bulk np-Au to the high volatility of the $\mathrm{AlMe}_{3}$ and $\mathrm{TiCl}_{4}$ precursors, and the low process temperature. ${ }^{40,41}$ Long pulse, pump and purge times (90 s each) were used to ensure uniform coatings throughout the porous material. Static conditions were used for $\mathrm{AlMe}_{3}, \mathrm{TiCl}_{4}$, and $\mathrm{H}_{2} \mathrm{O}$ pulses, during which the chamber was isolated from the vacuum line. The film thickness was controlled by adjusting the number of ALD cycles (2-30), and the growth rate per cycle was calculated from the measured mass gain, the known surface area of np-Au, and densities of $\mathrm{ALD} \mathrm{Al}_{2} \mathrm{O}_{3}$ and $\mathrm{TiO}_{2}$.

The morphology and composition of the ALD-modified np-Au samples was characterized by Scanning Electron Microscopy and Energy Dispersive Spectroscopy (SEM/EDAX). Coarsening of np-Au during annealing ( $2 \mathrm{~h} / 400-1000{ }^{\circ} \mathrm{C} /$ air) was assessed by cross-sectional SEM (XSEM). The mechanical properties (Young's modulus and hardness) were studied by conventional loadcontrolled nanoindentation using a Berkovich tip. Nanoindentation tests were performed on polished samples (polished before dealloying) using a constant loading rate of $500 \mu \mathrm{N} / \mathrm{s}$ with loads ranging from 200 to $5000 \mu \mathrm{N}$. A minimum of 49 indents was made on each sample, and the standard Oliver-Pharr method ${ }^{42}$ was used to determine modulus and hardness values from the load-displacement curves. The catalytic performance was evaluated using a continuous (plugflow) reactor made of a quartz glass tube (inner diameter $\sim 1.5 \mathrm{~cm}$ ) which was placed in an electrical oven for temperature control. The inlet gas stream consisted of a mixture of 4-20 vol. $\% \mathrm{CO}$ (Linde, 4.7) and 30 vol. \% $\mathrm{O}_{2}$ (Linde, 5.0) using He (Linde, 5.0) as a carrier gas (total flow set to $50 \mathrm{sccm})$. The gas composition at the reactor exit was analyzed online by an IR-GasAnalyzer (URAS 10E, Hartmann und Braun).

For both ALD processes, the normalized mass gain increased approximately linear with the number of ALD cycles (Figure 1). The $\mathrm{Al}_{2} \mathrm{O}_{3}$ growth rate is $\sim 0.25 \mathrm{~nm}$ per cycle assuming a density $^{41}$ of $\sim 2.8 \mathrm{~g} / \mathrm{cm}^{3}$ and a specific surface area of $\sim 3.6 \mathrm{~m}^{2}$ per gram np-Au (estimated from the ligament diameter of $\sim 54 \mathrm{~nm}$ ). This is approximately twice the value of the growth rate reported in the literature $\left(0.125 \mathrm{~nm}\right.$ per cycle at $\left.125^{\circ} \mathrm{C}\right),{ }^{41}$ which suggests some CVD contribution due to incomplete purging of the reactants trapped in the nanometer scale pores of our 200-300 $\mu \mathrm{m}$ thick samples (pore length/pore diameter $>10^{3}$ ). This, however, did not affect the uniformity of our samples as cross-sectional EDAX analysis confirmed the uniformity of the alumina coating across the sample cross section. Higher deposition rates $\left(0.15-0.3 \mathrm{~nm} \mathrm{Al}_{2} \mathrm{O}_{3}\right.$ per cycle) have also been observed for much thinner, 100 -nm-thick np-Au films. ${ }^{30,31}$ For titania, we observed a deposition rate of $\sim 0.07 \mathrm{~nm}$ per cycle, consistent with the value reported in the literature $\left(0.078 \mathrm{~nm}\right.$ per cycle at $\left.100^{\circ} \mathrm{C}\right) .^{40}$

Improving the thermal stability of $\mathrm{np}-\mathrm{Au}$ is very important for many potential applications in the fields of catalysis, sensorics and actuation as it opens the door for higher operating temperatures and increases the long term stability of the material. Our results demonstrate that 
nm-thick ALD coatings can effectively suppress coarsening of the nanoscale structure of np-Au thus preserving its high surface area. The results regarding annealing experiments on as-prepared and alumina-coated $\mathrm{np}-\mathrm{Au}$ samples are summarized in Figure 2a-e. The annealing behavior of uncoated samples is similar to that published in previous work, ${ }^{10,18,19}$ and demonstrates the thermal instability of this nanostructured material. The ligaments coarsen rapidly with increasing annealing temperature, for example, from $54 \pm 12 \mathrm{~nm}$ (as-prepared) to $630 \pm 130$ and $2850 \pm 850 \mathrm{~nm}$ after annealing at 600 and $900{ }^{\circ} \mathrm{C}$, respectively (Figure 2a). ALD coating with $\mathrm{Al}_{2} \mathrm{O}_{3}$ at $125{ }^{\circ} \mathrm{C}$ did only marginally increase of the characteristic length scale of the as-prepared material from 54 to $56 \mathrm{~nm}$. Once the material is coated, however, it is stable up to at least $900{ }^{\circ} \mathrm{C}$ which is almost $90 \%$ of the melting temperature of bulk gold. Even samples annealed at $1000{ }^{\circ} \mathrm{C}$ still show the original nanoporous structure (Figure 2e), but the finding that larger, well-facetted micrometersized Au crystals now decorate the outer surface of the np-Au sample (Figure 2d) suggests that $\mathrm{Au}$ starts to diffuse out of the alumina-coated Au ligaments. Interestingly, the breakdown of the stabilizing effect of the $\mathrm{Al}_{2} \mathrm{O}_{3}$ coating coincides with the crystallization temperature of the initially amorphous $\mathrm{Al}_{2} \mathrm{O}_{3}$ film. ${ }^{32,33}$

In one instance, we found several empty alumina 'shells' in a sample that was annealed at $600{ }^{\circ} \mathrm{C}$. This finding demonstrates two important points: (1) even few-nm-thick ALD alumina films are continuous, and (2) defects in the alumina coating drastically reduce the thermal stability. The thickness of the alumina films, on the other hand, does not seem to have a pronounced effect on the thermal stability, and even samples that were coated with sub-nm-thick alumina films (2 ALD cycles) were stable up to at least $900{ }^{\circ} \mathrm{C}$.

The mechanical behavior of np-Au is, for example, crucial for its actuator ${ }^{13,43}$ application where it controls the maximum stress that can be applied by the actuator. Here, we use nanoindentation to assess the mechanical properties of ALD-coated np-Au. Our results demonstrate that $\mathrm{Al}_{2} \mathrm{O}_{3}$ coatings make np-Au harder and stiffer which is summarized in Figure 3. As expected, both elastic modulus (Figure 3c) and hardness (Figure 3d) increase with increasing number of ALD cycles. Both hardness and stiffness further increase upon annealing at $600{ }^{\circ} \mathrm{C}$ (Figure $3 b$ ). The latter effect can be attributed to the densification of amorphous alumina films that occurs around this temperature. ${ }^{32}$ Crystallization, on the other hand, requires much higher annealing temperatures of $\sim 1000{ }^{\circ} \mathrm{C} .{ }^{32,33}$

In an attempt to better understand the effect of ALD coatings on the mechanical behavior of $\mathrm{np}-\mathrm{Au}$, we first applied the core-shell model developed by Liu et al. ${ }^{44}$ to estimate the mechanical behavior of the $\mathrm{Al}_{2} \mathrm{O}_{3}$-coated gold ligaments, and then used these values as an input to the Gibson-Ashby (G-A) scaling equations ${ }^{45}$ that correlate the properties of the individual ligaments with the bulk mechanical response of $\mathrm{np}-\mathrm{Au}$ as measured by nanoindentation experiments. ${ }^{20,39}$, 46, 47 According to the G-A scaling equations, the Young's modulus $E^{*}$ and yield strength $\sigma^{*}$ of $\mathrm{np}-\mathrm{Au}$ are related to the Young's modulus $E_{\mathrm{s}}$ and yield strength $\sigma_{\mathrm{s}}$ of the individual ligaments by

$$
E^{*}=C_{1} E_{s}\left(\frac{\rho^{*}}{\rho_{s}}\right)^{n_{1}} \quad \text { (1) and } \sigma^{*}=C_{2} \sigma_{s}\left(\frac{\rho^{*}}{\rho_{s}}\right)^{n_{2}}
$$

where $\rho^{*} / \rho_{\mathrm{s}}$ is the relative density of the material ( 0.3 in the present study). The proportionality constants $C_{1}$ and $C_{2}$ describe the cell geometry and the density exponents $n_{1}$ and $n_{2}$ depend on the elastic/plastic cell deformation mechanism. Experimental data obtained from macroscopic 
open-cell foam materials are usually well fitted by using $C_{1}=1 / n_{1}=2$ and $C_{2}=0.3 / n_{2}=3 / 2$, respectively. ${ }^{45}$ In the case of np-Au, however, a density exponent $n_{1}$ of 2 seems to underestimate the density dependence of $E^{*}{ }^{47}$ Here, we assume a value of $n_{1}=3$ that better describes the experimentally observed density dependence. ${ }^{47}$

According to Liu et al. ${ }^{44}$ the Young's modulus of core-shell structures depends on both the Young's modulus ( $E_{\text {core }}$ and $\left.E_{\text {shell }}\right)$ as well as on the fractional volumes $\left(V_{\text {core }} / V\right.$ and $\left.V_{\text {shell }} / V\right)$ of core and shell via

$$
E_{S}=\frac{V_{\text {core }}}{V} E_{\text {core }}+\frac{V_{\text {shell }}}{V} E_{\text {shell }}
$$

where $V_{\text {core, }} V_{\text {shell }}$ and $V$ are the volume of the core, shell, and core plus shell, respectively. $E_{\mathrm{s}}$ can then be calculated from the normalized mass gain data shown in Figure 1 using the Young's modulus of $\mathrm{Au}$ single crystals $(57-85 \mathrm{GPa})^{48}$ and ALD alumina films $(150 \mathrm{GPa})^{49,50}$ as reference. Inserting Eq. (3) into Eq. (1) then yields the predicted lower and upper bounds of $E^{*}$ of the $\mathrm{Al}_{2} \mathrm{O}_{3}$-coated $\mathrm{np}$-Au (red lines in Figure $3 \mathrm{c}$ ). This simple model describes the experimental data relatively well, although it predicts too high values for thicker ALD films. To check if the mechanical response of $\mathrm{Al}_{2} \mathrm{O}_{3}$-coated $\mathrm{np}$ - $\mathrm{Au}$ is simply the sum of its components, the $\mathrm{Au}$ core and the alumina shell, we also tested the mechanical properties of a free-standing alumina shell structure prepared by removing the $\mathrm{Au}$ core from a np-Au sample coated with $10 \mathrm{Al}_{2} \mathrm{O}_{3} \mathrm{ALD}$ cycles (details of the preparation and the mechanical properties will be described in an oncoming publication). The modulus of uncoated np-Au and the free-standing alumina shell are $1.83 \pm 0.08$ $\mathrm{GPa}$ and $0.14 \mathrm{GPa}$, repectively. It is clear that the sum of these components (blue data point in Figure $3 \mathrm{c}$ ) severely underestimates the effect of the $\mathrm{Al}_{2} \mathrm{O}_{3}$ coating on the Young's modulus of $\mathrm{np}-\mathrm{Au}$. In fact, the measured increase in the Young's modulus is almost 10 times the Young's modulus of the free-standing $\mathrm{Al}_{2} \mathrm{O}_{3}$ foam.

In analogy to Eq. (3), we also calculated the yield strength $\sigma_{\mathrm{s}}$ of $\mathrm{Al}_{2} \mathrm{O}_{3}$-coated $\mathrm{Au}$ ligaments using the yield strength of $50 \mathrm{~nm}$ Au ligaments $(\sim 1.1 \mathrm{GPa}$, obtained by applying Eq. (2) to uncoated $\mathrm{np}-\mathrm{Au})^{20,39}$ and ALD alumina $(\sim 2.7 \mathrm{GPa}, \sigma=\text { nanoindentation hardness } / 3)^{49}$ as reference. Insertion in Eq (2) then yields the predicted yield strength of $\mathrm{Al}_{2} \mathrm{O}_{3}$-coated np-Au shown as red line in Figure $3 \mathrm{~d}$. Although the agreement between experiment and model is reasonable for thin coatings, the experimentally observed strengthening of thicker films is severely underestimated. The alumina coating seems to shifts the critical stress level to even higher values than the already high value $(\sim 1 \mathrm{GPa})$ required to support plasticity in uncoated $\mathrm{Au}$ ligaments.

In the field of catalysis, the critical questions is if ALD coatings can be used to further improve the catalytic properties of np-Au while adding thermal stability for high temperature applications. To answer this question we studied the thermal stability and catalytic activity of $\mathrm{TiO}_{2}$-coated np-Au as it is known that the combination of $\mathrm{Au}$ and $\mathrm{TiO}_{2}$ leads to highly active catalysts. $^{25}$ The development of the ligament size vs. annealing temperature is shown in Figure $2 \mathrm{a}$, and representative morphology changes are shown in Figure 4 . $\mathrm{TiO}_{2}$ coatings also increase the thermal stability of $\mathrm{np}-\mathrm{Au}$, but less than the $\mathrm{Al}_{2} \mathrm{O}_{3}$ coatings discussed above. Annealing at $600{ }^{\circ} \mathrm{C}$ does only slightly increase the characteristic feature size of np-Au, but breaks up the initially continuous and smooth $\mathrm{TiO}_{2}$ coating into highly dispersed nanoparticles (Fig. 4, top 
panel). Above $600{ }^{\circ} \mathrm{C}$, the ligaments of $\mathrm{TiO}_{2}$-coated np-Au start to coarsen, but not as fast as those in uncoated np-Au. The thermal stability caused by metal oxide coatings seems to correlate better with the crystallization temperature $\left(\mathrm{TiO}_{2}: \sim 370{ }^{\circ} \mathrm{C},{ }^{51} \mathrm{Al}_{2} \mathrm{O}_{3}: \sim 900-1000{ }^{\circ} \mathrm{C}^{32,}{ }^{33}\right)$ than with the melting point $\left(\mathrm{TiO}_{2}: \sim 1843{ }^{\circ} \mathrm{C}, \mathrm{Al}_{2} \mathrm{O}_{3}: \sim 2053{ }^{\circ} \mathrm{C}\right)$. The slower coarsening kinetics, and the serrated structure of $\mathrm{TiO}_{2}$-coated $\mathrm{np}$-Au annealed at or above $700{ }^{\circ} \mathrm{C}$ can be attributed to step edge pinning by $\mathrm{TiO}_{2}$ nanoparticles that was also observed in $\mathrm{Au}$ single crystal experiments. ${ }^{52}$

The morphology of the $\mathrm{TiO}_{2} / \mathrm{Au}$ nanocomposite structures that results from annealing is very interesting for catalytic applications. Indeed, first catalytic tests using the oxidation of $\mathrm{CO}, \mathrm{CO}+$ $1 / 2 \mathrm{O}_{2} \rightarrow \mathrm{CO}_{2}$, as a test reaction already demonstrate the potential of ALD functionalization to design new np-Au catalysts with improved catalytic activity and thermal stability (Fig. 5). Pristine $\mathrm{TiO}_{2}$-coated $\mathrm{np}$-Au is catalytically in-active as titania itself is not active for $\mathrm{CO}$ oxidation ${ }^{53}$ and $\mathrm{TiO}_{2}$ completely covers the np-Au surface. After annealing at $600{ }^{\circ} \mathrm{C}$, however, $\mathrm{TiO}_{2}$-coated $\mathrm{np}$-Au shows an almost 3 times larger activity towards $\mathrm{CO}$ oxidation as compared to uncoated $\mathrm{np}-\mathrm{Au}$. In contrast, annealing of uncoated $\mathrm{np}-\mathrm{Au}$ at $600{ }^{\circ} \mathrm{C}$ decreases its activity by more than $50 \%$ which can be attributed to the loss of catalytically active surface area due to coarsening (see Fig. 2a). A comparison with Figure 4 reveals that annealing at $600{ }^{\circ} \mathrm{C}$ is sufficient to break up the initially continuous $\mathrm{TiO}_{2}$ film into $\mathrm{TiO}_{2}$ nanocrystals. The presence of these $\mathrm{TiO}_{2}$ nanocrystals on the surface of the ligaments of np-Au likely increases the efficiency for $\mathrm{O}_{2}$ dissociation as a source for atomic oxygen which is the rate limiting step for $\mathrm{CO}$ oxidation with gold based catalysts. ${ }^{25}$ The $\mathrm{TiO}_{2}$ coating also stabilizes the nanoscale structure of the material, and thus reduces the loss of catalytically active surface area during annealing/high temperature applications.

In conclusion, our results demonstrate that ALD functionalization offers an opportunity to drastically improve the thermal stability and mechanical properties of $\mathrm{np}-\mathrm{Au}$, and even increase the catalytic activity at the same time. For example, only one-nm-thick $\mathrm{Al}_{2} \mathrm{O}_{3}$ films can stabilize the nanoscale morphology of np-Au up to $1000^{\circ} \mathrm{C}$, and $\sim 6$-nm-thick films lead to a 3- and 7-fold increase in Young's modulus and hardness, respectively, while increasing the density by only $10 \%$. This also demonstrates that thin oxide films can have a pronounced effect on nanomechanical tests, and although np-Au itself is not a good choice for structural applications due to it's the high costs, our results demonstrate the potential of ALD coatings to improve the mechanical properties of other nanoscale materials, for example, for nanoelectromechanical systems (NEMS). Catalytic tests with $\mathrm{TiO}_{2}$ coated np-Au also demonstrate that ALD surface functionalization can improve the catalytic activity of np-Au. For example, the presence of highly dispersed $\mathrm{TiO}_{2}$ nanoparticles on Au ligaments, formed by annealing the initially smooth and continuous $\mathrm{TiO}_{2}$ film at $600{ }^{\circ} \mathrm{C}$, increases the catalytic activity towards $\mathrm{CO}$ oxidation by several hundred percent. The enhanced thermal stability combined with added functionally opens the door to many promising applications: For example, the plasmonic response of the nanoporous Au network ${ }^{2,10}$ allows for high temperature surface enhanced Raman spectroscopy. ${ }^{54}$ The desired pore size can first be "dialed in" by annealing uncoated np-Au, and then be frozen in by applying a nm-thick ALD coating. Improved thermal, mechanical and catalytic properties also enable high temperature actuator and catalysis applications. ${ }^{13,43}$ Metal oxide coated nanoporous metals are also promising electrode materials for batteries and energy harvesting and conversion applications. 
Acknowledgement. Work at LLNL was performed under the auspices of the U.S. DOE by LLNL under Contract DE-AC52-07NA27344. We gratefully acknowledge Prof. Andrea Hodge, University of Southern California, who provided polished samples for mechanical testing. 


\section{References:}

1. Wittstock, A.; Zielasek, V.; Biener, J.; Friend, C. M.; Baumer, M. Science 2010, 327, 319-322.

2. Dongqing, H.; Tingting, X.; Jixin, S.; Xiaohong, X.; Yi, D. ChemCatChem 2010, 2, 383-386.

3. Ding, Y.; Chen, M. W. MRS Bulletin 2009, 34, 569-576.

4. Jia, J.; Cao, L.; Wang, Z. Langmuir 2008, 24, 5932-5936.

5. Xu, C. X.; Su, J. X.; Xu, X. H.; Liu, P. P.; Zhao, H. J.; Tian, F.; Ding, Y. J. Am. Chem. Soc. 2007, 129, 4243.

6. Zielasek, V.; Jurgens, B.; Schulz, C.; Biener, J.; Biener, M. M.; Hamza, A. V.; Bäumer, M. Angew. Chem. Int. Ed. 2006, 45, 8241-8244.

7. Lang, X. Y.; Guo, H.; Chen, L. Y.; Kudo, A.; Yu, J. S.; Zhang, W.; Inoue, A.; Chen, M. W. J. Phys. Chem. C. 2010, 114, 2600-2603.

8. Lang, X. Y.; Guan, P. F.; Zhang, L.; Fujita, T.; Chen, M. W. Appl. Phys. Lett. 2010, 96, 073701.

9. Lang, X. Y.; Chen, L. Y.; Guan, P. F.; Fujita, T.; Chen, M. W. Appl. Phys. Lett. 2009, 94, 213109.

10. Biener, J.; Nyce, G. W.; Hodge, A. M.; Biener, M. M.; Hamza, A. V.; Maier, S. A. Adv. Mater. 2008, 20, 1211-1217.

11. Dixon, M. C.; Daniel, T. A.; Hieda, M.; Smilgies, D. M.; Chan, M. H. W.; Allara, D. L. Langmuir 2007, 23, 2414-2422.

12. Kucheyev, S. O.; Hayes, J. R.; Biener, J.; Huser, T.; Talley, C. E.; Hamza, A. V. Appl. Phys. Lett. 2006, 89, 053102.

13. Biener, J.; Wittstock, A.; Zepeda-Ruiz, L. A.; Biener, M. M.; Zielasek, V.; Kramer, D.; Viswanath, R. N.; Weissmuller, J.; Bäumer, M.; Hamza, A. V. Nat. Mater. 2009, 8, 47-51.

14. Kramer, D.; Viswanath, R. N.; Weissmueller, J. Nano Letters 2004, 4, 793-796.

15. Weissmüller, J.; Viswanath, R. N.; Kramer, D.; Zimmer, P.; Wuerschum, R.; Gleiter, H. Science 2003, 300, 312-315.

16. Erlebacher, J.; Aziz, M. J.; Karma, A.; Dimitrov, N.; Sieradzki, K. Nature 2001, 410, 450-453.

17. Erlebacher, J.; Sieradzki, K. Scripta Mater. 2003, 49, 991-996.

18. Li, R.; Sieradzki, K. Phys. Rev. Lett. 1992, 68, 1168-1171.

19. Kertis, F.; Snyder, J.; Govada, L.; Khurshid, S.; Chayen, N.; Erlebacher, J. JOM 2010, 62, 50-56.

20. Biener, J.; Hodge, A. M.; Hayes, J. R.; Volkert, C. A.; Zepeda-Ruiz, L. A.; Hamza, A. V.; Abraham, F. F. Nano Lett. 2006, 6, 2379-2382.

21. Snyder, J.; Asanithi, P.; Dalton, A. B.; Erlebacher, J. Adv. Mater. 2008, 20, 4883-+.

22. Xu, C. X.; Wang, R. Y.; Chen, M. W.; Zhang, Y.; Ding, Y. Phys. Chem. Chem. Phys. 2010, 12, 239-246.

23. Biener, J.; Wittstock, A.; Biener, M. M.; Nowitzki, T.; Hamza, A. V.; Baeumer, M. Langmuir 2010, 26, 13736-13740.

24. Ge, X. B.; Yan, X. L.; Wang, R. Y.; Tian, F.; Ding, Y. J. Phys. Chem. C. 2009, 113, 7379-7384.

25. Bond, G. C.; Thompson, D. T. Gold Bull. 2000, 33, 41-51.

26. Baumann, T. F.; Biener, J.; Wang, Y. M. M.; Kucheyev, S. O.; Nelson, E. J.; Satcher, J. H.; Elam, J. W.; Pellin, M. J.; Hamza, A. V. Chem. Mater. 2006, 18, 6106-6108.

27. Biener, J.; Baumann, T. F.; Wang, Y. M.; Nelson, E. J.; Kucheyev, S. O.; Hamza, A. V.; Kemell, M.; Ritala, M.; Leskela, M. Nanotechnol. 2007, 18, 055303.

28. George, S. M. Chem. Rev. 2010, 110, 111-131.

29. Lee, D.; Wei, X.; Chen, X.; Zhao, M.; Jun, S. C.; Hone, J.; Herbert, E. G.; Oliver, W. C.; Kysar, J. W. Scripta Mater. 2007, 56, 437-440.

30. Qian, L. H.; Shen, W.; Das, B.; Shen, B.; Qin, G. W. W. Chem. Phys. Lett. 2009, 479, 259-263.

31. Qian, L. H.; Shen, W.; Shen, B.; Qin, G. W. W.; Das, B. Nanotechnol. 2010, 21, 305705.

32. Jakschik, S.; Schroeder, U.; Hecht, T.; Gutsche, M.; Seidl, H.; Bartha, J. W. Thin Solid Films 2003, 425, 216-220. 
33. Katamreddy, R.; Inman, R.; Jursich, G.; Soulet, A.; Nicholls, A.; Takoudis, C. Thin Solid Films 2007, 515, 6931-6937.

34. Standridge, S. D.; Schatz, G. C.; Hupp, J. T. Langmuir 2009, 25, 2596-2600.

35. Linsebigler, A. L.; Lu, G. Q.; Yates, J. T. Chem. Rev. 1995, 95, 735-758.

36. Jia, C. C.; Yin, H. M.; Ma, H. Y.; Wang, R. Y.; Ge, X. B.; Zhou, A. Q.; Xu, X. H.; Ding, Y. J. Phys. Chem. C. 2009, 113, 16138-16143.

37. Cheah, S. K.; Perre, E.; Rooth, M.; Fondell, M.; Hårsta, A.; Nyholm, L.; Boman, M.; Gustafsson, T.; Lu, J.; Simon, P.; Edström, K. Nano Lett. 2009, 9, 3230-3233.

38. Robertson, J. Rep. Prog. Phys. 2006, 69, 327-396.

39. Hodge, A. M.; Biener, J.; Hayes, J. R.; Bythrow, P. M.; Volkert, C. A.; Hamza, A. V. Acta Mater. 2007, 55, 1343-1349.

40. Aarik, J.; Aidla, A.; Mändar, H.; Uustare, T. Appl. Surf. Sci. 2001, 172, 148-158.

41. Groner, M. D.; Fabreguette, F. H.; Elam, J. W.; George, S. M. Chem. Mater. 2004, 16, 639-645.

42. Oliver, W. C.; Pharr, G. M. J. Mater. Res. 1992, 7, 1564-1583.

43. Kramer, D.; Viswanath, R. N.; Weissmüller, J. Nano Lett. 2004, 4, 793-796.

44. Liu, X. W.; Hu, J.; Pan, B. C. Physica E 2008, 40, 3042-3048.

45. Gibson, L. J.; Ashby, M. F., Cellular Solids: Structure and Properties. 2nd. ed.; Cambridge University Press: Cambridge, UK, 1997.

46. Biener, J.; Hodge, A. M.; Hamza, A. V.; Hsiung, L. M.; Satcher, J. H. J. Appl. Phys. 2005, 97, 024301.

47. Hodge, A. M.; Doucette, R. T.; Biener, M. M.; Biener, J.; Cervantes, O.; Hamza, A. V. J. Mater. Res. 2009, 24, 1600-1606

48. Kiely, J. D.; Houston, J. E. Phys. Rev. B 1998, 57, 12588-12594.

49. Herrmann, C. F.; DelRio, F. W.; George, S. M.; Bright, V. M., Properties of atomic layer deposited Al2O3/ZnO dielectric films grown at low temperature for RF MEMS. In Micromachining and Microfabrication Process Technology X, Maher, M. A.; Stewart, H. D., Eds. 2005; Vol. 5715, pp 159166.

50. Tripp, M. K.; Stampfer, C.; Miller, D. C.; Helbling, T.; Hermann, C. F.; Hierold, C.; Gall, K.; George, S. M.; Bright, V. M. Sensors and Actuators A 2006, 130, 419-429.

51. Yin, S.; Inoue, Y.; Uchida, S.; Fujishiro, Y.; Sato, T. J. Mater. Res. 1998, 13, 844-847.

52. Biener, J.; Farfan-Arribas, E.; Biener, M.; Friend, C. M.; Madix, R. J. J. Chem. Phys. 2005, 123, 094705.

53. Diebold, U. Surf. Sci. Rep. 2003, 48, 53-229.

54. Whitney, A. V.; Elam, J. W.; Stair, P. C.; Van Duyne, R. P. J. Phys. Chem. C. 2007, 111, 16827-16832. 


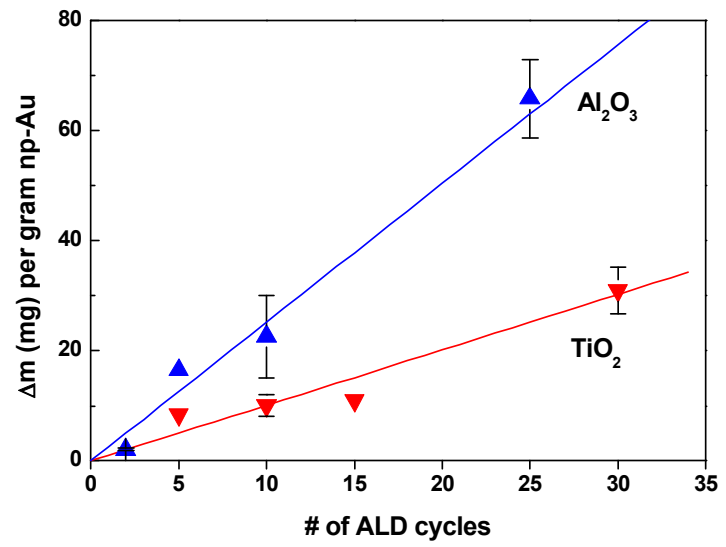

Figure 1: Normalized mass gain per gram np-Au vs. number of ALD cycles for both $\mathrm{Al}_{2} \mathrm{O}_{3}$ and $\mathrm{TiO}_{2}$ deposition. The normalized mass gain increases approximately linear with the number of ALD cycles, and the growth rates are $\sim 0.25$ and $\sim 0.07 \mathrm{~nm}$ per cycle for $\mathrm{Al}_{2} \mathrm{O}_{3}$ and $\mathrm{TiO}_{2}$, respectively. Error bars indicate the standard deviation obtained from 3 or more individual coating experiments. 

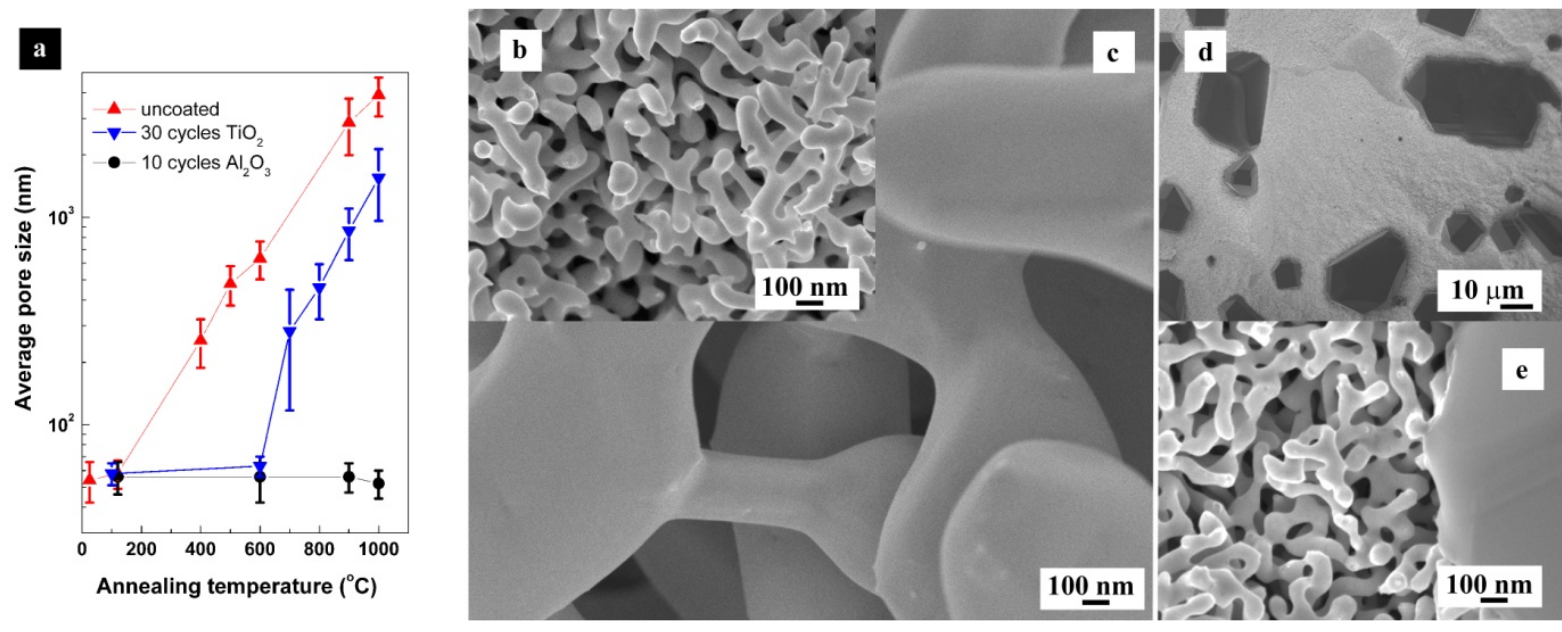

Figure 2: Thermal stability of $\mathrm{Al}_{2} \mathrm{O}_{3}$ - and $\mathrm{TiO}_{2}$-coated np-Au: (a) development of average ligament size of $\mathrm{Al}_{2} \mathrm{O}_{3}$ - (10 cycles), $\mathrm{TiO}_{2-}$ (30 cycles), and un-coated np-Au vs. annealing temperature; SEM micrographs obtained from (b) $\mathrm{Al}_{2} \mathrm{O}_{3}$-coated (10 cycles) and (c) uncoated np$\mathrm{Au}$ after annealing at $600{ }^{\circ} \mathrm{C}$; (d-e) surface of an alumina-coated npAu sample after annealing at $1000{ }^{\circ} \mathrm{C}$ imaged at different magnifications. After annealing at $1000{ }^{\circ} \mathrm{C}$, the surface is covered with micron-sized Au crystallites (d), but the nanoscale structure of np-Au is still intact (e). 
回

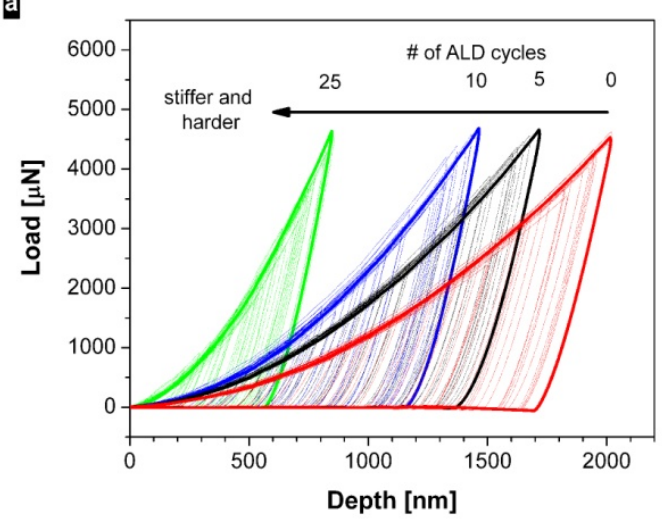

c

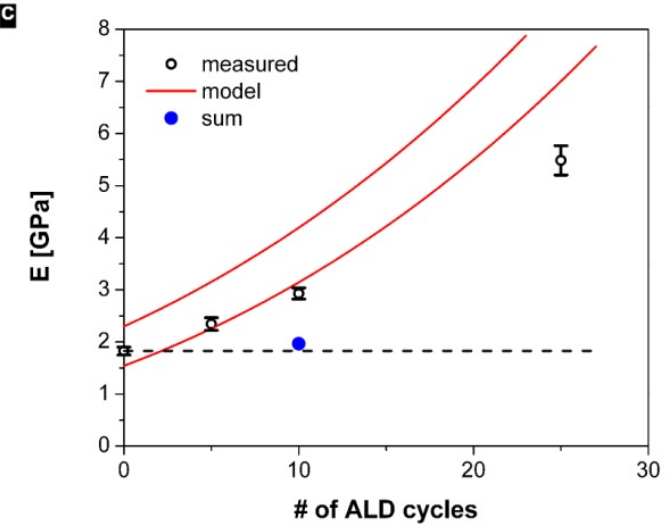

b

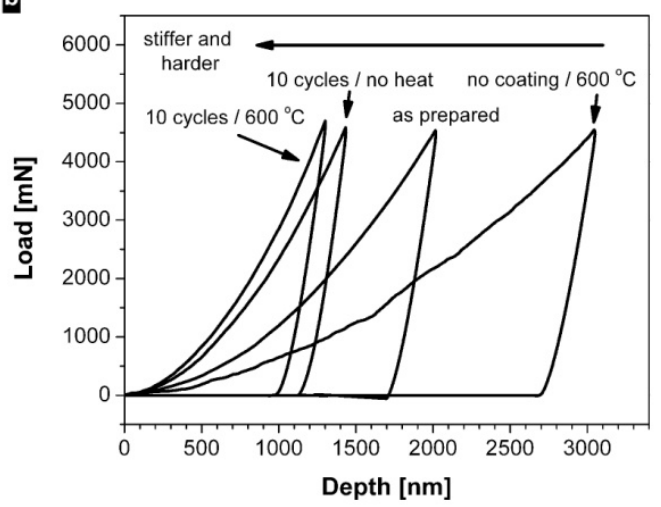

d

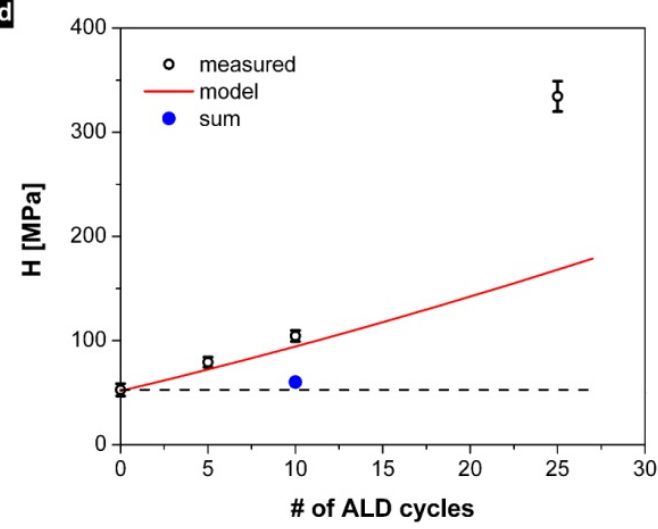

Figure 3: Mechanical properties of $\mathrm{Al}_{2} \mathrm{O}_{3}$-coated np-Au samples: (a) Nanoindentation loaddisplacement curves of np-Au samples coated with $0,5,10$, and 25 ALD cycles, respectively. (b) Effect of annealing on the load-displacement nanoindentation curves for both coated (10 ALD cycles) and uncoated np-Au samples; Young's modulus (c) and Hardness (d) versus number of ALD cycles obtained from the nanoindentation data shown in (a), and values predicted by the core-shell model. 


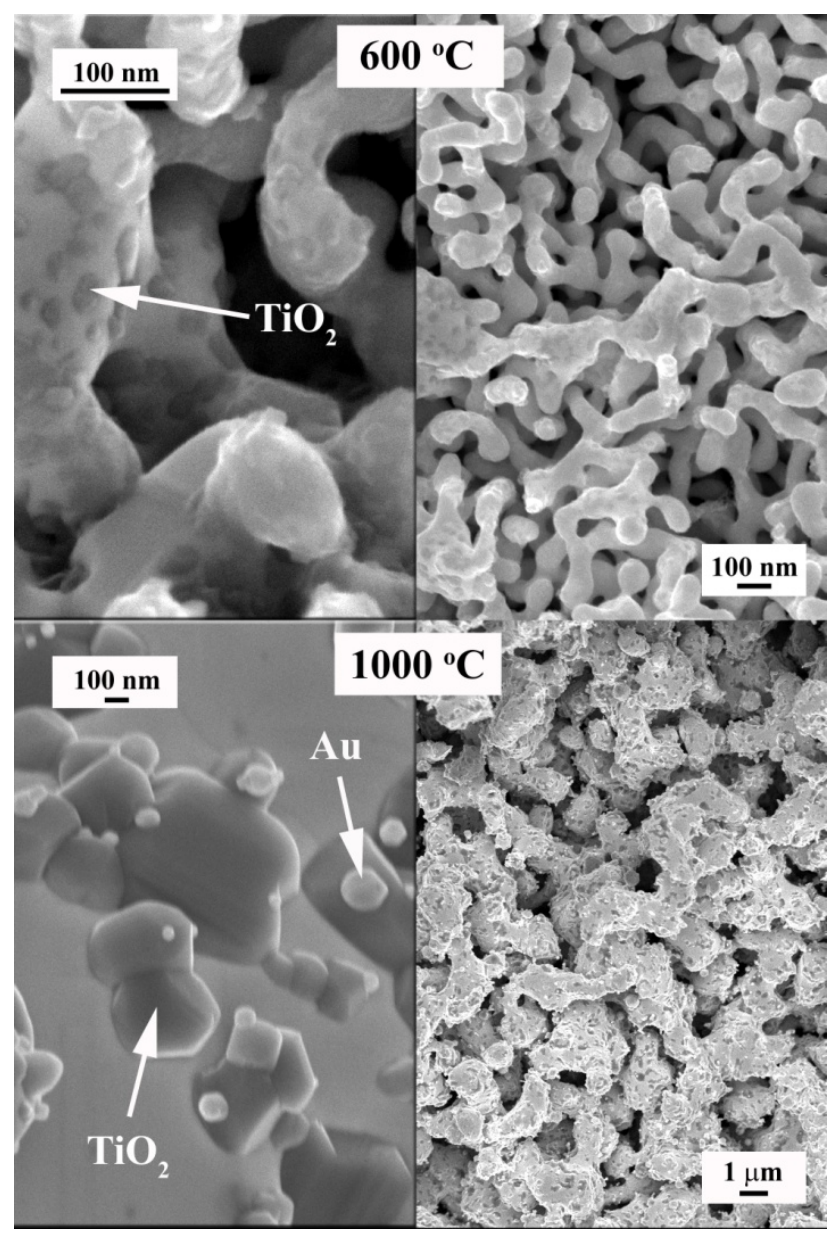

Figure 4: SEM micrographs showing representative morphological changes of $\mathrm{TiO}_{2}$-coated (30 cycles) np-Au films upon annealing at $600{ }^{\circ} \mathrm{C}$ (top) and $1000{ }^{\circ} \mathrm{C}$ (bottom), respectively. Annealing at $600{ }^{\circ} \mathrm{C}$ does only slightly increase the characteristic feature size of np-Au (see also figure 2a), but breaks up the initially continuous and smooth $\mathrm{TiO}_{2}$ coating (not shown) into highly dispersed nanoparticles (top panel). Coarsening of the Au ligaments is observed during annealing at or above $700{ }^{\circ} \mathrm{C}$. At $1000{ }^{\circ} \mathrm{C}$, for example, this leads to the formation of micronsized ligaments decorated with well-facetted $\mathrm{TiO}_{2}$ crystals that are sometimes decorated with $\mathrm{Au}$ nano-crystals. Elemental composition of the different features was verified with area-specific EDAX. 


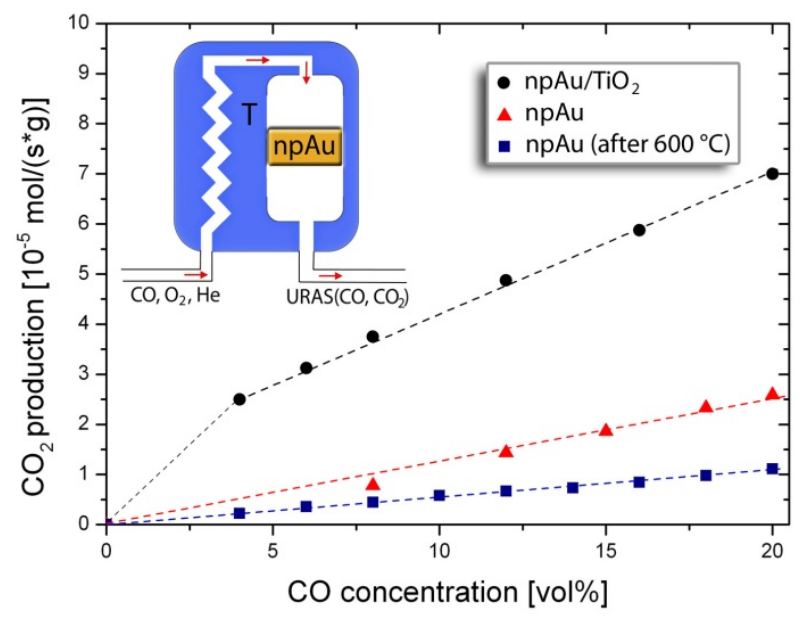

Figure 5:.Comparison of the catalytic activity of a $\mathrm{TiO}_{2}$ modified (10 $\mathrm{ALD}$ cycles/annealed at $600{ }^{\circ} \mathrm{C}$ ) np-Au sample with an uncoated np-Au sample before and after annealing a $600{ }^{\circ} \mathrm{C}$ in He. Shown is the catalytic activity towards $\mathrm{CO}$ oxidation measured at $60^{\circ} \mathrm{C}$ using $4-20$ vol. \% $\mathrm{CO}$ and 30 vol. $\% \mathrm{O}_{2}$ in a $\mathrm{He}$ carrier gas. Titania-coating causes a 3-fold increase in the catalytic activity with respect to the uncoated, not annealed np-Au sample, while annealing of the uncoated np-Au sample at $600{ }^{\circ} \mathrm{C}$ decreases its reactivity by more than $50 \%$. 